\title{
Hydroxycinnamoyl Esters of Malic Acid in Small Radish (Raphanus sativus L. var. sativus)
}

\author{
Wilfried Brandl and Karl Herrmann \\ Institut für Lebensmittelchemie der Universität Hannover, Wunstorfer Str. 14, D-3000 Hannover \\ and \\ Lutz Grotjahn \\ Gesellschaft für Biotechnologische Forschung, Mascheroder Weg 1, D-3300 Braunschweig \\ Z. Naturforsch. 39 c, 515-520 (1984); received March 6, 1984

\begin{abstract}
Hydroxycinnamoylmalic Acids, Isolation, Identification, Quantitative Determination, Raphanus sativus

The esters of $p$-coumaric, ferulic and caffeic acid with malic acid were isolated from leaves, the ester of sinapic acid with malic acid from cotyledons of Raphanus sativus plants via preparative HPLC. The esters were identified by hydrolyses and following capillary GC, by H-NMR and FAB-MS. Their concentrations in leaves and tubers were determined by gradient HPLC on reversed phase material.
\end{abstract}

\section{Introduction}

Hydroxycinnamic acid derivatives are present ubiquitously in the plant kingdom [1]. They have been detected in small radish by paper and thin layer chromatographic techniques [2]. Some of these compounds, especially those in small radish containing sinapic acid, could be analyzed by the investigations of Strack et al. [3, 4]. Two hydroxycinnamoylmalic acids are known up to now. Germs and leaves of beans (Phaseolus vulgaris) and red clover (Trifolium pratense) are containing caffeoylmalic acid (phaseolic acid) [5, 6] and sinapoylmalic acid has been determined in small radish seedlings.

In this present study, we report the occurrence of four hydroxycinnamoylmalic acids in small radish, the known esters of caffeic and sinapic acid and also the hithertoo unknown esters of $p$-coumaric and ferulic acid.

\section{Materials and Methods}

\section{Plant material}

Leaves of the small radish varieties Hilmar, Riesenbutter and Cherry Bell were used for the isolation and determination of $p$-coumaroyl, caffeoyl and feruloylmalic acid. To obtain sinapoylmalic acid, seed of the variety Rota was sown on cotton

Reprint requests to Dr. K. Herrmann.

0341-0382/84/0600-0515 \$01.30/0 in the laboratory. The cotyledons were harvested and worked up 11 days after sowing [4].

\section{Isolation of hydroxycinnamoylmalic acids}

Sinapoylmalic acid: The cotyledons were communited in methanol and homogenized using a mixer and an Ultra Turrax. After filtering the plant pulp through a $\mathrm{G} 4$ glass frit and washing the residue with hot methanol the extract was evaporated at $40{ }^{\circ} \mathrm{C}$ to about $30 \mathrm{ml}$ in vacuo. Sinapoylmalic acid was separated from the extract by preparative HPLC [7].

Apparatus: preparative HPLC system LCX (Philips), injection valve: Rheodyne 7125 with $2 \mathrm{ml}$ sample loop, detection: UV $320 \mathrm{~nm}$, solvent: $17 \%$ acetonitrile in $1 \%$ acetic acid, flow: $11.2 \mathrm{ml} / \mathrm{min}$, column: $250 \times 16 \mathrm{~mm}$, LiChrosorb RP $18,10 \mu \mathrm{m}$ (Chrompack).

The fractions containing sinapoylmalic acid $\left(t_{\mathrm{R}}=5.4 \mathrm{~min}\right)$ were collected and lyophylisated. The purity of the compound was checked by analytical HPLC.

\section{p-Coumaroyl, caffeoyl and feruloylmalic acid}

A $300 \mathrm{~g}$ amount of small radish leaves was worked up to obtain these esters. They were isolated by preparative HPLC using the solvent $13 \%$ acetonitrile in $1 \%$ acetic acid. Retention times: caffeoylmalic acid: $t_{\mathrm{R}}=15.6 \mathrm{~min}, p$-courmaroylmalic acid: $t_{\mathrm{R}}=27.3 \mathrm{~min}$, feruloylmalic acid: $t_{\mathrm{R}}=32.7 \mathrm{~min}$. The 
fractions collected were lyophylisated and the purity of the obtained compounds was controlled by analytical HPLC. The fractions containing $p$-coumaroylmalic acid and feruloylmalic acid were cleaned up once more by preparative HPLC (solvent: 15\% acetonitrile in $1 \%$ acetic acid).

\section{Identification of the hydroxycinnamoylmalic acid components by $G C$}

For the identification of the components of hydroxycinnamoylmalic acids about $1 \mathrm{mg}$ of each compound was hydrolyzed by adding $0.5 \mathrm{ml}$ of $0.5 \mathrm{~N}$ $\mathrm{HCl}$ and refluxing for 7 minutes in boiling water. The hydrolysate was evaporated to dryness in vacuo and trimethylsilylated by adding $0.5 \mathrm{ml}$ BSA/ $5 \%$ TMCS and heating at $70^{\circ} \mathrm{C}$ for 60 minutes. $p$-Coumaric, caffeic, ferulic, sinapic, malic and pimelic acid (internal standard) were treated in the same way for reference.

Apparatus: capillary GC (Carlo Erba), capillary: SE 30, 30 m (self made), carrier: $\mathrm{N}_{2}$, detector: FID, temperatur gradient: $120^{\circ} \mathrm{C}-8^{\circ} \mathrm{C} / \mathrm{min}-220^{\circ} \mathrm{C}-$ $15^{\circ} \mathrm{C} / \min -270^{\circ} \mathrm{C}$.

The hydroxycinnamic acid and malic acid could be detected in about equimolar ratio in each case.

\section{$H-N M R$}

H-NMR were recorded on a Bruker WH 270 spectrometer with puls fourier transformation techniques. DMSO $\mathrm{d}_{6}$ (solvent) was assigned $2.5 \mathrm{ppm}$ as secondary standard.

\section{$F A B-M S$}

Negativion mass spectra were recorded on a Kratos MS $50 \mathrm{~S}$ spectrometer with a Kratos FAB source. A Xenon atom gun was used at $9 \mathrm{KV}$.

\section{Quantitative determinations}

The quantitative determinations were performed with: HPLC system LCX (Philips), injection valve: Rheodyne 7125 with $20 \mu$ l sample loop, column: $250 \times 4.6 \mathrm{~mm}$, LiChrosorb RP 18, $5 \mu \mathrm{m}$ (Merck), detector: UV $320 \mathrm{~nm}$, integrator: DP 101 Computing Integrator (Pye Unicam), solvent: $\mathrm{A}=2 \%$ acetic acid, $\mathrm{B}=$ methanol, gradient: $5 \% \mathrm{~B}$ in $\mathrm{A}-45 \% \mathrm{~B}$ in A in 45 minutes, flow: $1 \mathrm{ml} / \mathrm{min}$.

\section{Results and Discussion}

The isolated compounds were identified as trans p-coumaroylmalic acid, trans-caffeoylmalic acid, trans-feruloylmalic acid and trans-sinapoylmalic acid by acid hydrolysis and following identification of the components via GC, by H-NMR and negativion FAB-MS.<smiles>[R]c1cc(C=CC(=O)OC(CC(=O)O)C(=O)O)cc([R7])c1O</smiles>

Characteristic proton signals of the hydroxycinnamic acids and malic acid could be detected by NMR (Table I). The coupling of the doublets $(16 \mathrm{~Hz})$ of the olefinic protons makes possible the determination of the trans compounds. The shift of about $5.2 \mathrm{ppm}$ of the $\mathrm{CH}$-proton of malic acid allows the identification of the ester bond with malic acid as alcoholic component (malic acid: $\delta(\mathrm{CH})=4.27 \mathrm{ppm})$.

Negativion $F A B$ mass spectroscopy affords a very good method for the mass spectrometric characterisation of conjugates, produced by plant cells, when they are bonded by oxygen. As well as intense deprotonated molecular ions characteristic sequence ions are also found. In the present compounds, conjugates of malic acid with $p$-coumaric acid, or ferulic acid, or caffeic acid, or sinapic acid show intense molecular ions at 279, 295, 309 and $339 \mathrm{~d}$ respectively. Cleavage of the bond between the ester oxygen of malic acid and the carbonyl of the aromatic acid gives the malic acid sequence ion at $133 \mathrm{~d}$, while the characteristic aromatic acid sequence ions for cleavage between the carbon of the malic acid and the ester oxygen affords ions at $163 \mathrm{~d}$ for $p$-coumaric acid, $179 \mathrm{~d}$ for caffeic acid, $193 \mathrm{~d}$ for ferulic acid and $223 \mathrm{~d}$ for sinapic acid. Glycerol was used as matrix for the measurements and this gives rise to ions at 91, 183, 275 and $367 \mathrm{~d}$ (Figs. 1-4).

For the first time every possible ester of hydroxycinnamic acids with malic acid has been characterized and identified side by side in one plant. The thin layer characteristics $\left(h R_{f}\right)$ of these esters are differing significantly from other hydroxycinnamic acid esters (Table II), facilitating their qualitative determination beside the frequently present esters with quinic acid or glucose. 
Table I. H-NMR of hydroxycinnamoylmalic acids in DMSO $\mathrm{d}_{6}$.

\begin{tabular}{|c|c|c|c|c|c|c|c|c|}
\hline & $p-\mathrm{CM}$ & ppm & $\mathrm{CM}$ & ppm & FM & ppm & $\mathrm{SM}$ & ppm \\
\hline 1 & Ar.-H & $7.59 \mathrm{~d} 15 \mathrm{~Hz}$ & $\mathrm{OH}$ & & $\mathrm{OCH}_{3}$ & $3.82 \mathrm{~s}$ & $\mathrm{OCH}_{3}$ & $3.81 \mathrm{~s}$ \\
\hline 2 & Ar.-H & $7.59 \mathrm{~d} 15 \mathrm{~Hz}$ & Ar.-H & $6.77 \mathrm{~d} 8 \mathrm{~Hz}$ & Ar.-H & $7.14 \mathrm{~d} 8 \mathrm{~Hz}$ & $\mathrm{OCH}_{3}$ & $3.81 \mathrm{~s}$ \\
\hline 3 & Ar.-H & $6.80 \mathrm{~d} 15 \mathrm{~Hz}$ & Ar.-H & $7.03 \mathrm{~m}$ & Ar.-H & $6.80 \mathrm{~d} 8 \mathrm{~Hz}$ & Ar.-H & $7.04 \mathrm{~s}$ \\
\hline 4 & Ar.-H & $6.80 \mathrm{~d} 15 \mathrm{~Hz}$ & Ar.-H & $7.03 \mathrm{~m}$ & Ar.-H & $7.35 \mathrm{~s}$ & Ar.-H & $7.04 \mathrm{~s}$ \\
\hline 5 & olef.-H & 7.58 unres. & olef.-H & $7.46 \mathrm{~d} 17 \mathrm{~Hz}$ & olef.-H & 7.60 unres. & olef.-H & $7.54 \mathrm{~d} 16 \mathrm{~Hz}$ \\
\hline 6 & olef.-H & $6.46 \mathrm{~d} 14 \mathrm{~Hz}$ & olef.-H & $6.27 \mathrm{~d} 17 \mathrm{~Hz}$ & olef.-H & 6.55 unres. & olef.-H & $6.54 \mathrm{~d} 16 \mathrm{~Hz}$ \\
\hline 7 & alk.-H & 5.24 unres. & alk.-H & $5.15 \mathrm{dd} 8 \mathrm{~Hz}$ & alk.-H & 5.23 unres. & alk.-H & $5.08 \mathrm{dd} 2 \mathrm{~Hz}$ \\
\hline 8 & alk.-H & $3.27 \mathrm{~s}$ & alk.-H & $3.10 \mathrm{~s}$ & alk.-H & $3.26 \mathrm{~s}$ & alk.-H & $3.11 \mathrm{~s}$ \\
\hline
\end{tabular}

p-CM, p-coumaroylmalic acid; CM, caffeoylmalic acid; FM, feruloylmalic acid; SM, sinapoylmalic acid; d, doublet; dd, double doublet; s, singlet; unres., unresolved.

Table II. Thin layer chromatography $\left(\mathrm{h} \mathrm{R}_{\mathrm{f}}\right)$ of hydroxycinnamoylmalic acids on cellulose plates.

\begin{tabular}{llllllll}
\hline & BAW & BPW & KFW & EMW & UV & UV + NH & UV + Ben. \\
\hline $\begin{array}{l}\text { p-coumaroylmalic acid } \\
\text { caffeoylmalic acid }\end{array}$ & 92 & 17 & 97 & 96 & nv & blue & blue \\
feruloylmalic acid & 79 & 11 & 89 & 96 & blue & green & brown \\
sinapoylmalic acid & 90 & 15 & 96 & 96 & blue & green & blue \\
& 81 & 8 & 93 & 95 & blue & green & green \\
\hline
\end{tabular}

BAW, butanol/acetic acid/water $=40 / 10 / 50$ (upper layer); BPW, butanol/pyridine/water $=14 / 3 / 3$; KFW, methylisobutylketone/formic acid/water = 30/10/20 (upper layer); EMW, ethylacetate/methanol/water = 200/35/27; Ben., Benedicts reagens; nv, not visible.
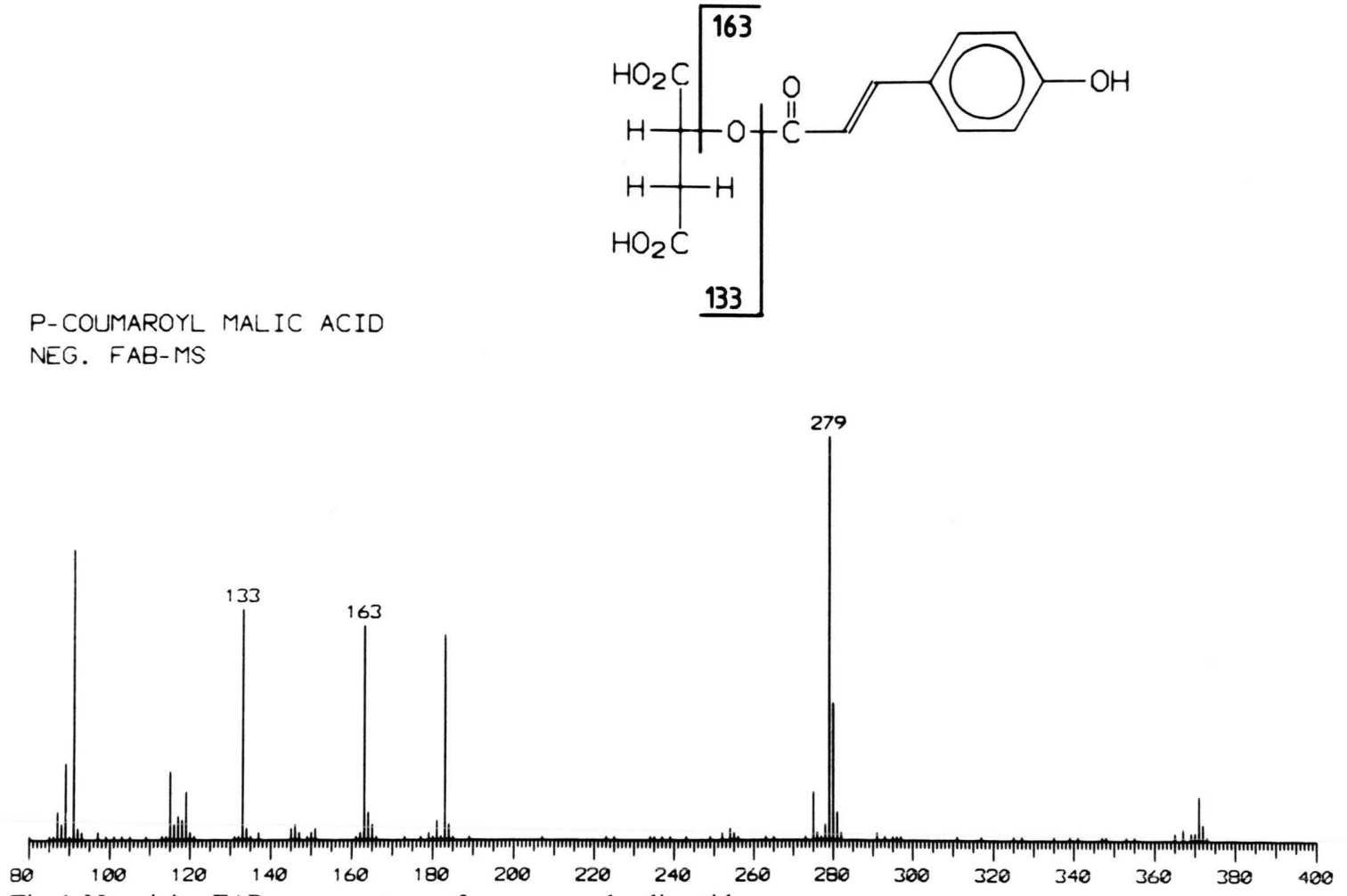

Fig. 1. Negativion FAB mass spectrum of $p$-coumaroylmalic acid. 


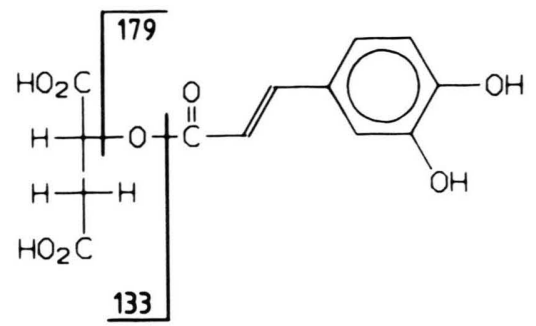

CAFFEOYL MALIC ACID

NEG. FAB-MS

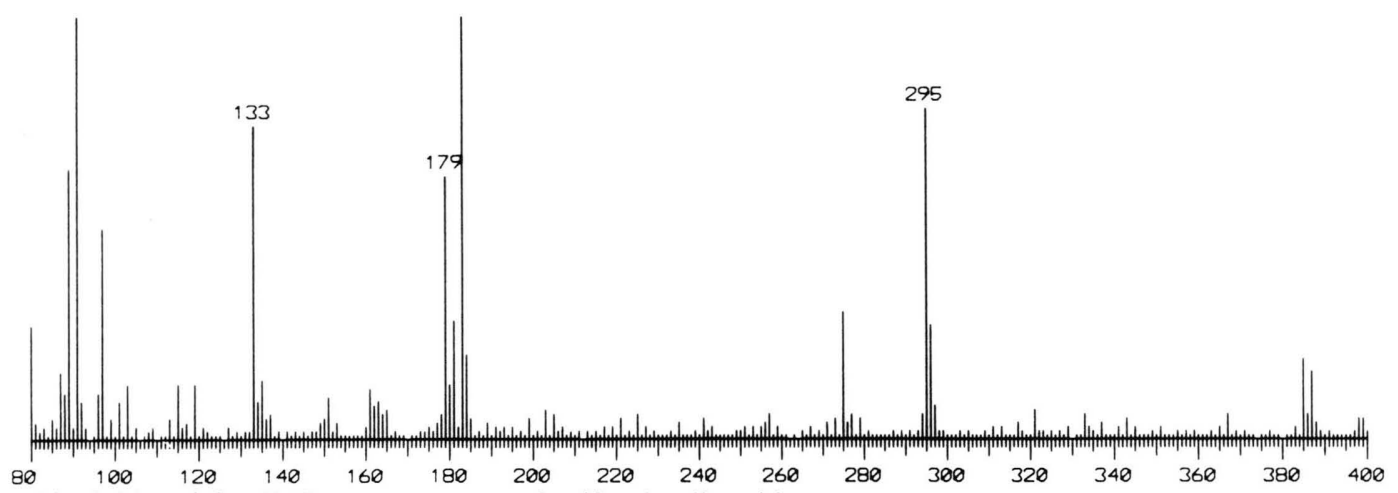

Fig. 2. Negativion FAB mass spectrum of caffeoylmalic acid.



FERULOYL MALIC ACID

NEG. FAB-MS

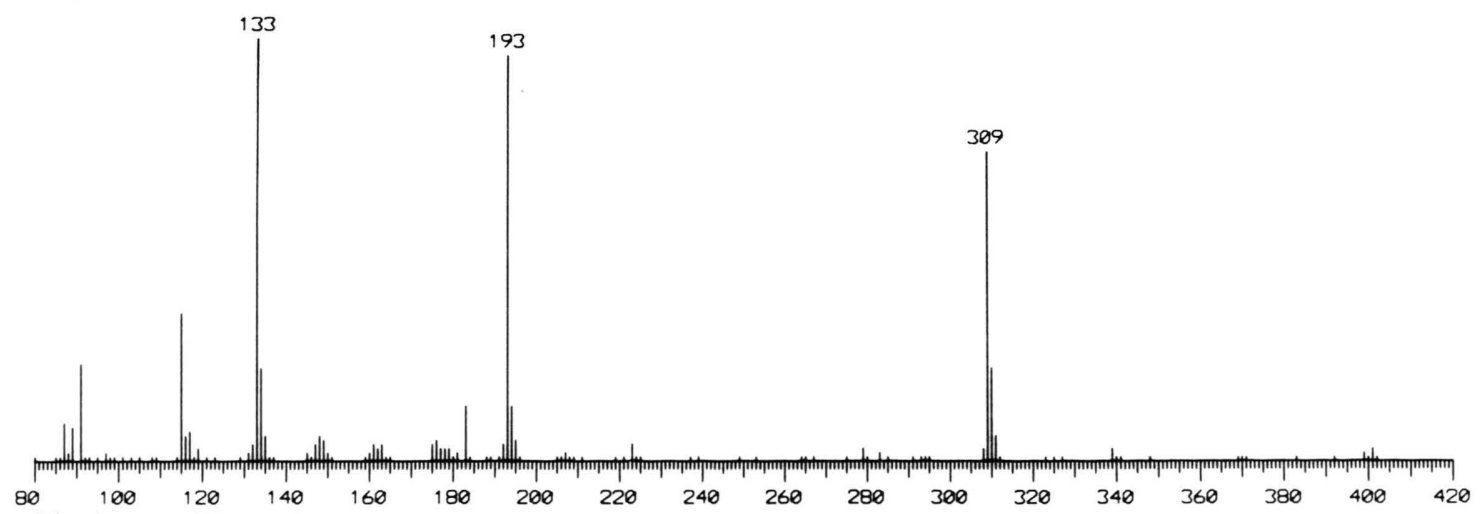

Fig. 3. Negativion FAB mass spectrum of feruloylmalic acid. 


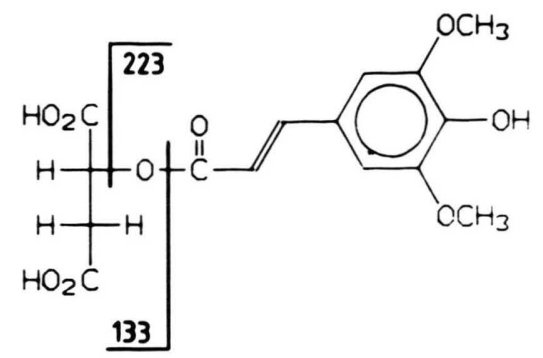

SINAPOYL MALIC ACID

NEG. FAB-MS

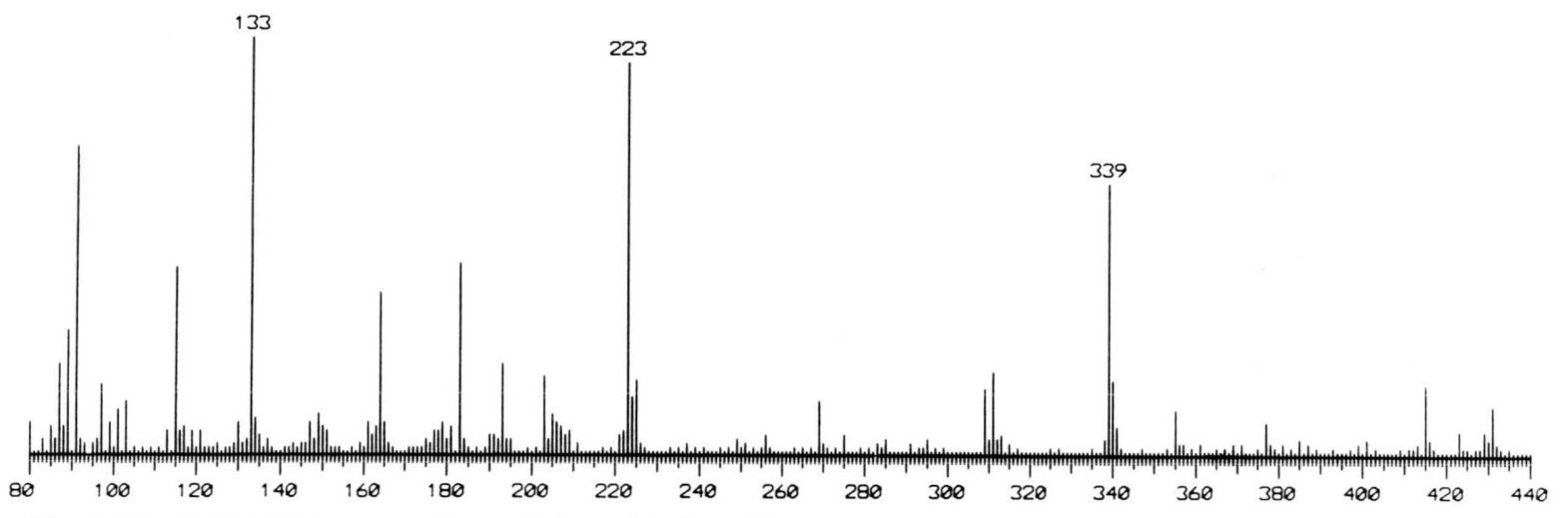

Fig. 4. Negativion FAB mass spectrum of sinpoylmalic acid.

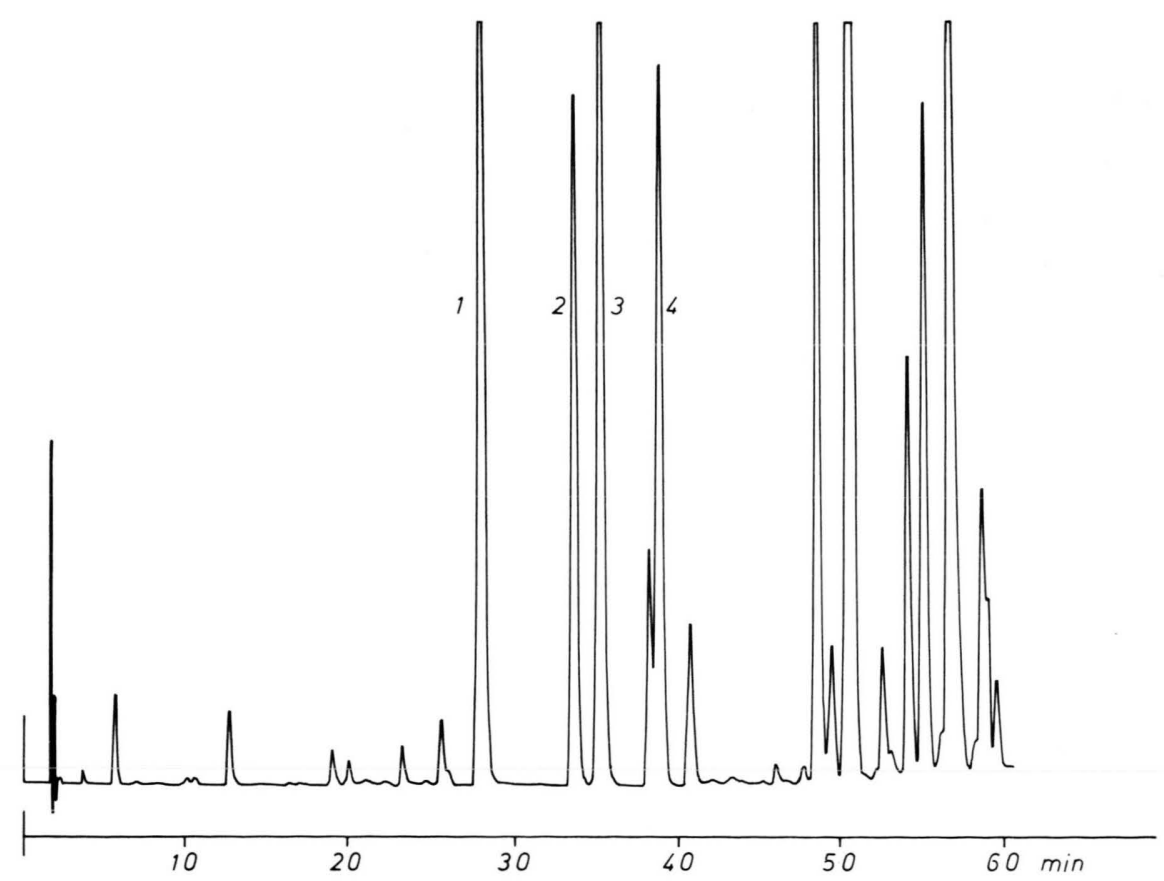

Fig. 5. HPLC chromatogram of Raphanus sativus leaves ("Hilmar"). 1, caffeoylmalic acid; 2, p-coumaroylmalic acid; 3, feruloylmalic acid; 4 , sinapoylmalic acid. 
Table III. Concentrations of hydroxycinnamoylmalic acids in Raphanus sativus in ppm.

\begin{tabular}{|c|c|c|c|c|c|c|c|c|c|}
\hline & $p-\mathrm{CM}$ & $\mathrm{CM}$ & FM & $\mathrm{SM}$ & $3 \mathrm{CQ}$ & $5 \mathrm{CQ}$ & $\mathrm{CG}$ & $p-\mathrm{CG}$ & $\mathrm{FG}$ \\
\hline \multicolumn{10}{|l|}{ "Hilmar" } \\
\hline $\begin{array}{l}\text { leaves } \\
\text { tuber peeling } \\
\text { tuber peeled }\end{array}$ & $\begin{array}{r}43 \\
4 \\
\text { nd }\end{array}$ & $\begin{array}{r}80 \\
19 \\
2\end{array}$ & $\begin{array}{r}81 \\
10 \\
2\end{array}$ & $\begin{array}{r}56 \\
8 \\
2\end{array}$ & $\begin{array}{r}1 \\
2 \\
\text { nd }\end{array}$ & $\begin{array}{l}+ \\
+ \\
\text { nd }\end{array}$ & $\begin{array}{l}6 \\
2 \\
+\end{array}$ & $\begin{array}{l}3 \\
+ \\
\text { nd }\end{array}$ & $\begin{array}{l}3 \\
2 \\
\text { nd }\end{array}$ \\
\hline \multicolumn{10}{|l|}{ "Riesenbutter" } \\
\hline $\begin{array}{l}\text { leaves } \\
\text { tuber peeling } \\
\text { tuber peeled }\end{array}$ & $\begin{array}{r}44 \\
3 \\
\text { nd }\end{array}$ & $\begin{array}{r}137 \\
53 \\
4\end{array}$ & $\begin{array}{l}88 \\
33 \\
13\end{array}$ & $\begin{array}{r}62 \\
30 \\
6\end{array}$ & $\begin{array}{r}2 \\
\text { nd } \\
\text { nd }\end{array}$ & $\begin{array}{l}2 \\
1 \\
\text { nd }\end{array}$ & $\begin{array}{l}6 \\
2 \\
\text { nd }\end{array}$ & $\begin{array}{l}2 \\
\text { nd } \\
\text { nd }\end{array}$ & $\begin{array}{l}3 \\
1 \\
+\end{array}$ \\
\hline \multicolumn{10}{|l|}{ "Cherry Bell”" } \\
\hline $\begin{array}{l}\text { leaves } \\
\text { tuber peeling } \\
\text { tuber peeled }\end{array}$ & $\begin{array}{l}79 \\
10 \\
\text { nd }\end{array}$ & $\begin{array}{r}255 \\
11 \\
1\end{array}$ & $\begin{array}{r}156 \\
7 \\
1\end{array}$ & $\begin{array}{l}60 \\
14 \\
\text { nd }\end{array}$ & $\begin{array}{c}2 \\
\text { nd } \\
\text { nd }\end{array}$ & $\begin{array}{l}1 \\
1 \\
\text { nd }\end{array}$ & $\begin{array}{l}7 \\
1 \\
+\end{array}$ & $\begin{array}{l}2 \\
\text { nd } \\
\text { nd }\end{array}$ & $\begin{array}{l}3 \\
1 \\
+\end{array}$ \\
\hline
\end{tabular}

p-CM, p-coumaroylmalic acid; CM, caffeoylmalic acid; FM, feruloylmalic acid; SM, sinapoylmalic acid; 3CQ, 3-caffeoylquinic acid; 5CQ, 5-caffeoylquinic acid; CG, caffeoylglucose; $p$-CG, p-coumaroylglucose; FG, feruloylglucose; nd, not detected; + , traces.

The hydroxycinnamoylmalic acids are present in relative high concentrations in the leaves of small radish (Table III, Fig. 5). Lower but still considerable amounts are located in the red coloured peeling. In peeled small radish the concentrations are substantially lower, similar to observations at other cultivated plants like potatoes [8]. As in other cultivated plants the concentrations of these hydroxycinnamoyl derivatives might be depending on vari-

[1] K. Herrmann, Progr. Chem. Organ. Nat. Products 35, 73 (1978).

[2] J. B. Harborne and J. J. Corner, Biochem. J. 81, 242 (1961).

[3] N. Tkotz and D. Strack, Z. Naturforsch. 35c, 835 (1980).

[4] D. Strack, Z. Pflanzenphysiol. 84, 139 (1977).

[5] M. L. Scarpati and G. Oriente, Gazz. Chim. Ital. 90, $212(1960)$. ety. Hydroxycinnamoylquinic acids and glucose were analyzed in addition to the hydroxycinnamoylmalic acids only in very low concentrations (Table III).

\section{Acknowledgements}

We wish to thank Mr. R. Römer (Medizinische Hochschule Hannover) for recording the H-NMR spectra. The work was supported by a grant from Deutsche Forschungsgemeinschaft.

[6] T. Yoshihara, H. Yoshikawa, S. Sakamura and T. Sakuma, Agric. Biol. Chem. (Tokyo) 38, 1107 (1974).

[7] W. Brandl and K. Herrmann, J. Chromatogr. 260, 447 (1983).

[8] W. Brandl and K. Herrmann, Z. Lebensm.-Unters. Forsch. 178, 192 (1984). 